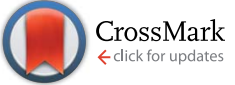

Cite this: RSC Adv., 2016, 6, 21736

\title{
Reliable resistive switching memory based on oxygen-vacancy-controlled bilayer structures $\uparrow$
}

\author{
Kyuhyun Park and Jang-Sik Lee*
}

We fabricated resistive random access memory (RRAM) devices composed of a bilayer of $\mathrm{AlO}_{x}$. The $A l O_{x}$ layer was synthesized by atomic layer deposition (ALD) with different oxidizer sources. To control the number of oxygen vacancies, we used water and ozone as the oxidizer sources in ALD. The AlO layer synthesized using water as the oxidizer source $\left(\mathrm{AlO}_{x}\right.$ (water)) contained more oxygen vacancies than the $\mathrm{AlO}_{x}$ layer deposited using ozone as the oxidizer $\left(\mathrm{AlO}_{x}\right.$ (ozone)). We fabricated memory devices with a structure of $\mathrm{Al} / \mathrm{AlO}_{x}($ water $) / \mathrm{AlO}_{x}$ (ozone)/Pt by ALD. After the initial forming process the devices showed reproducible and reliable RRAM characteristics. Bipolar resistive change was observed in $\mathrm{Al} / \mathrm{AlO}_{x}$ (water)/ $\mathrm{AlO}_{x}$ (Ozone)/Pt RRAM devices with low operation voltages of less than $1 \mathrm{~V}$. Ohmic conduction behavior was dominant in the low resistance state and trap-controlled space-charge-limited conduction was observed in the high resistance state. The resistive switching is related to migration of oxygen vacancies and the formation/rupture of conductive filaments. Oxygen vacancies formed conductive filaments when an electric field was applied, and Joule heating broke them. The reliability of the devices was confirmed by data retention and endurance tests. The reliable bipolar resistive switching properties are attributed to a stable conductive filament in the $\mathrm{AlO}_{x}$ (water) layer and partial connection/disruption of a conductive filament localized at the $\mathrm{AlO}_{x}$ (ozone) layer.

Received 11th January 2016

Accepted 16th February 2016

DOI: $10.1039 / c 6 r a 00798 \mathrm{~h}$

www.rsc.org/advances
To solve these problems, atomic layer deposition (ALD) has been used to deposit stoichiometry-controlled oxide layers. ALD is based on self-limiting reaction so it has unique characteristic such as ability to deposit very uniform thin films, and to control thickness at the atomic scale. To use ALD to deposit stoichiometry-controlled oxide layers, many researchers have varied ALD conditions such as precursor exposure time, oxidizer, deposition temperature, and inert gas. ${ }^{23-25}$

Moreover, to obtain reliable memory switching, a bilayer structure such as $\mathrm{WO}_{x} / \mathrm{NbO}_{x}, \mathrm{AlO}_{x} / \mathrm{WO}_{x}, \mathrm{HfO}_{x} / \mathrm{AlO}_{x}, \mathrm{ZrO}_{x} / \mathrm{HfO}_{y}$, $\mathrm{TiO}_{x} / \mathrm{HfO}_{x}, \mathrm{TaO}_{x} / \mathrm{WO}_{x}$, and $\mathrm{TiO}_{x} / \mathrm{TaO}_{x}$ has been used in the resistive switching layer in RRAM devices. ${ }^{26-34}$ Bilayer RRAM can provide good RRAM characteristics such as reliable and uniform electrical properties; stable resistive switching characteristics. $^{26-34}$

In this paper, we report use of ALD to control the amount of $\mathrm{V}_{\mathrm{o}} \mathrm{S}$ in $\mathrm{AlO}_{x}$ (water) $/ \mathrm{AlO}_{x}$ (ozone) bilayer structures. The first $\mathrm{AlO}_{x}$ layer was deposited using an ozone oxidizer; the second was deposited using a water oxidizer. The deposition temperature was $300{ }^{\circ} \mathrm{C}$ and the purging gas was Ar. The bottom electrode was $\mathrm{Pt}$ and top electrode was active $\mathrm{Al}$ which can induce $\mathrm{V}_{\mathrm{O}} \mathrm{S}$ in the $\mathrm{AlO}_{x}$ (water) layer. $\mathrm{AlO}_{x}$ (water) layer contains more $\mathrm{V}_{\mathrm{o}} \mathrm{s}$ than does the $\mathrm{AlO}_{x}$ (ozone) layer. $\mathrm{Al} / \mathrm{AlO}_{x}$ (water) $/ \mathrm{AlO}_{x}$ (ozone)/Pt bilayer RRAM can provide reliable retention characteristic, uniform switching voltages and stable resistance switching properties compared to single oxide layer-based RRAM.
Department of Materials Science and Engineering, Pohang University of Science and Technology (POSTECH), Pohang 790-784, Korea.E-mail: jangsik@postech.ac.kr

$\dagger$ Electronic supplementary information (ESI) available. See DOI: 10.1039/c6ra00798h 


\section{Experimental}

To fabricate the bilayer $\mathrm{Al} / \mathrm{AlO}_{x}$ (water) $/ \mathrm{AlO}_{x}$ (ozone)/Pt structures (Fig. 1), a $10 \mathrm{~nm}$ Ti layer was deposited on $\mathrm{SiO}_{2} / \mathrm{Si}$ substrate as adhesion layer by e-beam evaporation in a vacuum of $\sim 5 \times 10^{-6}$ Torr. Then a Pt bottom electrode was deposited by sputtering. $\mathrm{AlO}_{x}$ was deposited by ALD at $300{ }^{\circ} \mathrm{C}$. The metal precursor was trimethylaluminum (TMA) and the oxidation source was water $\left(\mathrm{AlO}_{x}(\right.$ water $\left.)\right)$ and ozone $\left(\mathrm{AlO}_{x}\right.$ (ozone)). Ar was used as the purging gas during ALD. After deposition of the Pt bottom electrode $3 \mathrm{~nm}$ of $\mathrm{AlO}_{x}$ was deposited using an ozone as the oxidation source. Then $3 \mathrm{~nm}$ of $\mathrm{AlO}_{x}$ was deposited using a water as the oxidation source. Finally, Al top electrodes with diameter of $100 \mu \mathrm{m}$ and thickness of $100 \mathrm{~nm}$ were deposited on the $\mathrm{AlO}_{x}$ layer by e-beam evaporation through a shadow mask. The current-voltage $(I-V)$ characteristic, data retention, and endurance were measured using a semiconductor parameter analyzer (4200-SCS, KEITHLEY) at room temperature (RT) and atmospheric pressure, except the data retention measurement, which was also performed at $85^{\circ} \mathrm{C}$ and $125^{\circ} \mathrm{C}$. During electrical measurements the Pt bottom electrode was electrically grounded, and external bias was applied to the Al top electrode.

\section{Results and discussion}

The $I-V$ curves of the $\mathrm{Al} / \mathrm{AlO}_{x}(5 \mathrm{~nm}) / \mathrm{Pt}$ devices exhibit a bipolar resistive switching under compliance current (CC) of $100 \mu \mathrm{A}$ (Fig. 2). We synthesized the single layer of $\mathrm{AlO}_{x}$ by ALD under water or ozone oxidizer. The $\mathrm{AlO}_{x}$ (ozone) layer was more insulating than the $\mathrm{AlO}_{x}$ (water) layer. The $\mathrm{AlO}_{x}$ (water) seems to have more $\mathrm{V}_{\mathrm{o}} \mathrm{s}$ than $\mathrm{AlO}_{x}$ (ozone) layers; i.e., that the stoichiometry of $\mathrm{AlO}_{x}$ layer can be controlled by selecting an appropriate oxidizer. ${ }^{35,36}$ Initial states of single layer-RRAM devices are shown in Fig. S1. $\dagger$ In addition, resistive switching behavior of single-layer RRAM device with $\mathrm{AlO}_{x}$ (water) is shown in Fig. S2. $\dagger$

The $I-V$ characteristics of $\mathrm{Al} / \mathrm{AlO}_{x}$ (water) $/ \mathrm{AlO}_{x}$ (ozone) $/ \mathrm{Pt}$ devices exhibit bipolar resistive switching under $\mathrm{CC}=100 \mu \mathrm{A}$ (Fig. 3a). A forming process is generally needed for RRAM that exploits conductive filaments. In the forming process to form conductive filaments; a high voltage is required to overcome the high resistance state of pristine state. After the forming process, negative bias was applied from 0 to $-2 \mathrm{~V}$ without a CC. After initial forming under positive bias, the $\mathrm{Al} / \mathrm{AlO}_{x}$ (water) $/ \mathrm{AlO}_{x^{-}}$ (ozone)/Pt RRAM devices showed stable and uniform bipolar switching behavior. The forming voltage was observed at $1.5 \mathrm{~V}$

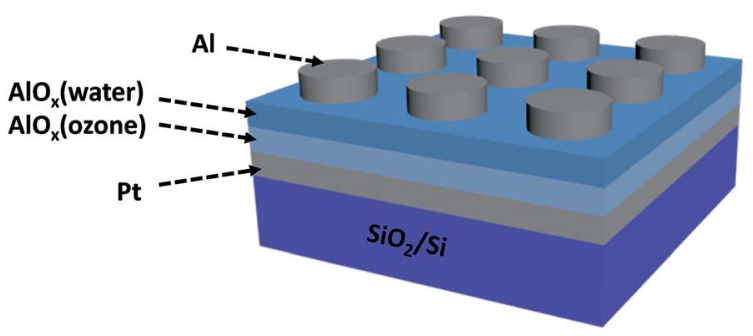

Fig. 1 Schematic of $\mathrm{Al} / \mathrm{AlO}_{x}\left(\right.$ water)/AlO ${ }_{x}$ (ozone)/Pt bilayer structures.

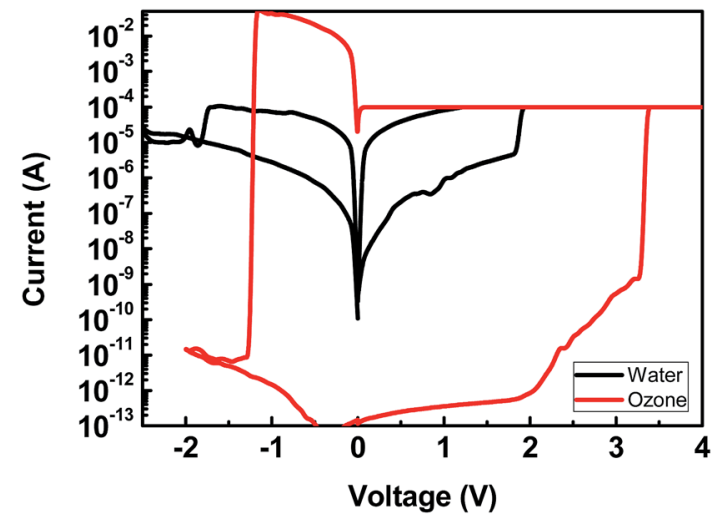

Fig. $2 \mathrm{I}-\mathrm{V}$ characteristic of $\mathrm{Al} / \mathrm{AlO}_{x}($ water, $5 \mathrm{~nm}) / \mathrm{Pt}$ and $\mathrm{Al} / \mathrm{AlO} \mathrm{O}_{x}$ (ozone, $5 \mathrm{~nm}$ )/Pt structure.

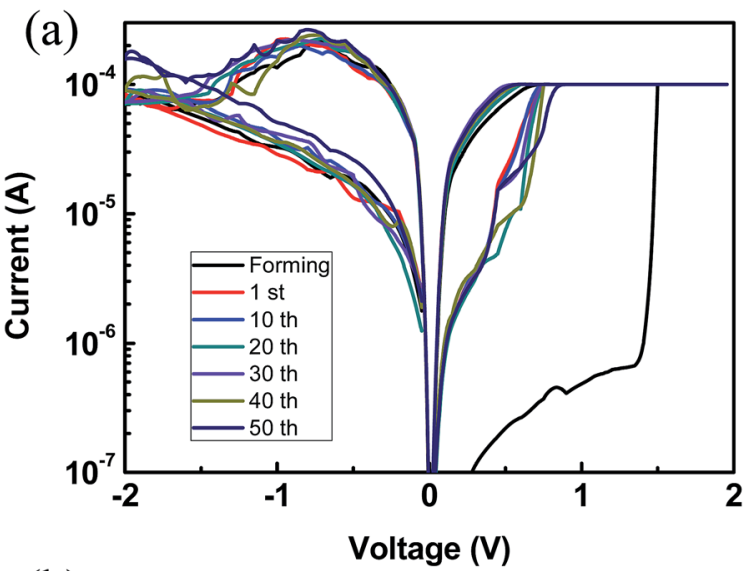

(b)

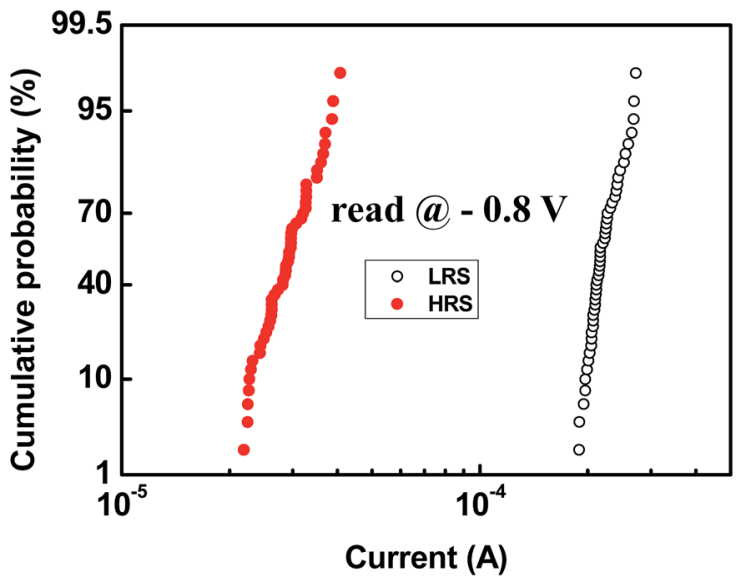

Fig. 3 (a) Typical I-V characteristics of $\mathrm{Al} / \mathrm{AlO}_{x}$ (water)/AlO $($ ozone)/Pt and (b) cumulative probability of current values read at $-0.8 \mathrm{~V}$.

and CC was $100 \mu \mathrm{A}$. During the second voltage sweep at positive bias, the device changed from the high-resistance state (HRS, OFF state) to a low-resistance state (LRS, conductive ON state). External bias was applied to the devices by sweeping the voltage from 0 to $2 \mathrm{~V}$. When the negative bias was applied, the current declined gradually after $-0.8 \mathrm{~V}$ and the resistance changed from LRS to HRS. After this reset process, a positive voltage was 
applied from 0 to $2 \mathrm{~V}$, with $\mathrm{CC}=100 \mu \mathrm{A}$. Current increased rapidly at set voltage $V_{\text {set }}=0.6 \mathrm{~V}$. These $I-V$ characteristics were measured under consecutive dc voltage sweeps $(0 \mathrm{~V} \rightarrow 2 \mathrm{~V} \rightarrow$ $0 \mathrm{~V} \rightarrow-2 \mathrm{~V} \rightarrow 0 \mathrm{~V}$ ). Voltage was controlled by the Al top electrode. To investigate the distribution of HRS and LRS currents, a cumulative distribution of current was calculated using a single cell at $-0.8 \mathrm{~V}$ (read voltage) during 50 cycles (Fig. $3 \mathrm{~b}$ ).

To determine the mechanisms of conduction and resistive switching of $\mathrm{Al} / \mathrm{AlO}_{x}$ (water) $/ \mathrm{AlO}_{x}$ (ozone)/Pt structured RRAM devices, a double logarithmic plot of the $I-V$ curve was drawn in HRS and LRS (Fig. 4). At low bias $(<0.4 \mathrm{~V})$ the slopes of the fitted lines in the double logarithmic plot were 1.001 at HRS and 1.014 at LRS; the similarity of the slope to ' 1 ' indicates that conduction behavior is ohmic $(I \propto V)$. In HRS under high bias $(>0.4 \mathrm{~V})$, the slope of this line increased to 2.792; this is the Child's law region. As the bias increased past the voltage required for the transition from the ohmic to the space-charge-limited-current (SCLC) regime, injected carriers dominated the conduction behavior. $^{37,38}$

To investigate the resistive switching mechanism, we measured RRAM devices with $\mathrm{Al} / \mathrm{AlO}_{x}$ (water) $/ \mathrm{AlO}_{x}$ (ozone)/Pt structure as above, and compared their characteristics to RRAM devices with $\mathrm{Al} / \mathrm{AlO}_{x}$ (ozone) $/ \mathrm{AlO}_{x}$ (water)/Pt structure (i.e., $\mathrm{AlO}_{x}$ layers exchanged) while applying positive or negative bias at the top electrode. $\mathrm{Al} / \mathrm{AlO}_{x}$ (water)/ $/ \mathrm{AlO}_{x}$ (ozone)/Pt devices exhibited reliable $I-V$ characteristic, gradual reset behavior, well-behaved bipolar filamentary switching and good uniformity under application of positive bias first (Fig. 5a), but unstable $I-V$ characteristic, abrupt reset behavior and poor uniformity under application of negative bias first (Fig. 5b). In contrast, $\mathrm{Al} / \mathrm{AlO}_{x}($ ozone $) / \mathrm{AlO}_{x}$ (water)/Pt devices exhibited unstable $I-V$ characteristic, abrupt reset behaviour, and poor uniformity (Fig. 5c) under application of positive bias first, and unstable $I-V$ characteristics, gradual reset behaviour, and poor uniformity (Fig. 5d) under application of negative bias first.

To determine how the Al top electrode affects the device, we fabricated one with a $\mathrm{Pt}$ top electrode instead of an $\mathrm{Al}$ top electrode. The $I-V$ characteristics of the $\mathrm{Pt} / \mathrm{AlO}_{x}$ (water) $/ \mathrm{AlO}_{x^{-}}$ (ozone)/Pt RRAM were similar to those of the $\mathrm{Al} / \mathrm{AlO}_{x}$ (water)/ $\mathrm{AlO}_{x}$ (ozone)/Pt devices, such as the gradual reset behavior, set

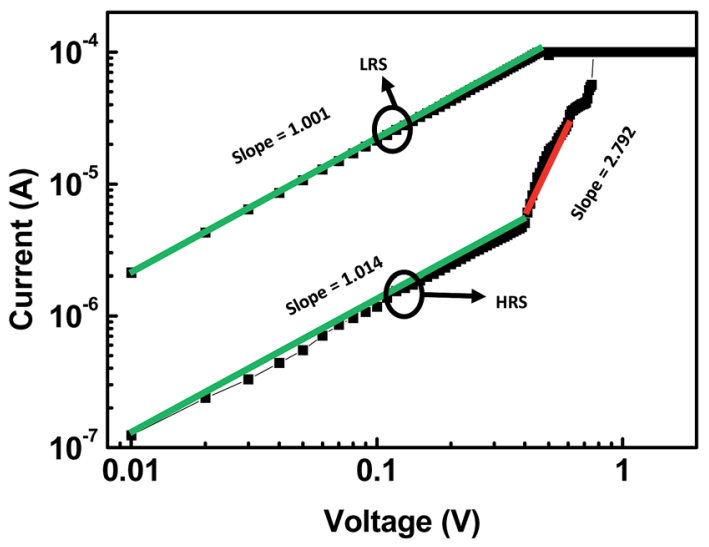

Fig. 4 Double logarithmic plot of LRS and HRS regions. Linear fitting is shown in the figure.
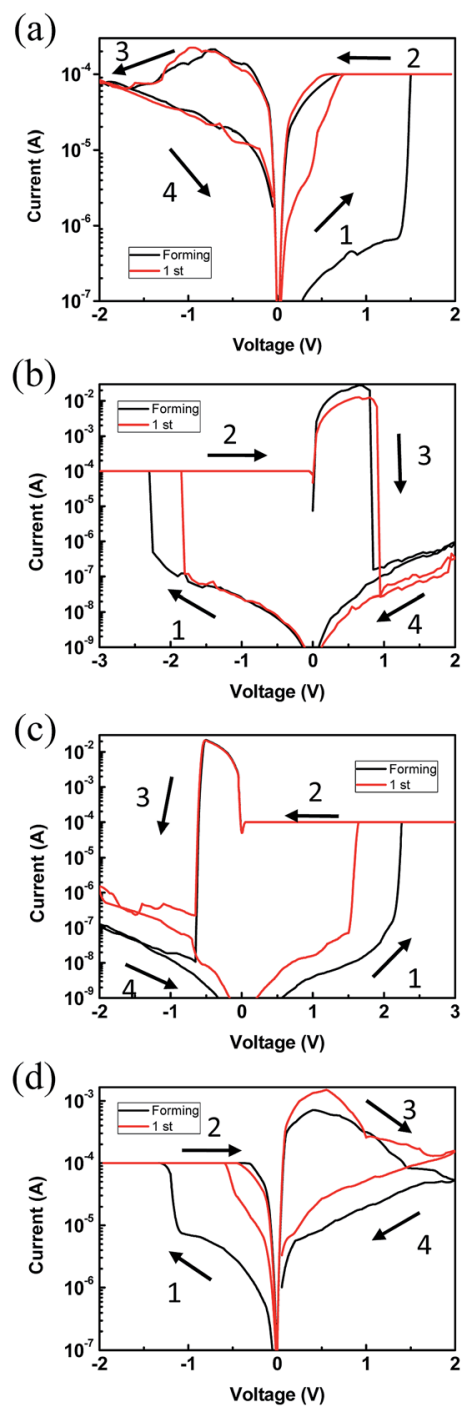

Fig. $5 \mathrm{I}-\mathrm{V}$ characteristic of $\mathrm{Al} / \mathrm{AlO}_{x}($ water $) / \mathrm{AlO}_{x}($ ozone) $/ \mathrm{Pt}$ with application of (a) positive bias first and (b) negative bias first. I-V characteristic of $\mathrm{Al} / \mathrm{AlO}_{x}(\mathrm{Ozone}) / \mathrm{AlO}_{x}$ (water)/Pt structure with application of (c) positive bias first and (d) negative bias first.

and reset voltage (Fig. 6). However, the $\mathrm{Pt} / \mathrm{AlO}_{x}$ (water)/ $/ \mathrm{AlO}_{x^{-}}$ (ozone)/Pt devices were not reliable. Only the devices with $\mathrm{Al}$ top electrode showed stable switching behavior.

These results suggest that the switching mechanism of $\mathrm{Al} /$ $\mathrm{AlO}_{x}$ (water) $/ \mathrm{AlO}_{x}$ (ozone)/Pt devices is based on the difference in the number of $\mathrm{V}_{\mathrm{o}} \mathrm{S}$ in the two $\mathrm{AlO}_{x}$ layers. The $\mathrm{AlO}_{x}$ (water) layer has a large number $\mathrm{V}_{\mathrm{O}} \mathrm{s}$, so conductive filaments remain stable, whereas the $\mathrm{AlO}_{x}$ (ozone) layer has few $\mathrm{V}_{\mathrm{o}} \mathrm{s}$, the conductive filaments partially disassociate. When negative bias is applied, electrons move from the top electrode to the bottom electrode. During this process, the current density increases in interface between $\mathrm{AlO}_{x}$ (water) and $\mathrm{AlO}_{x}$ (ozone) layer, and conductive filaments partially dissociate in the top part of $\mathrm{AlO}_{x}$ (Ozone) layer (Fig. 7). The active Al top electrode which contacts the $\mathrm{AlO}_{x}$ layer deposited using water oxidant increases the number of $\mathrm{V}_{\mathrm{o}} \mathrm{S}$ in $\mathrm{AlO}_{x}$ (water). It will be very important to know the exact oxygen vacancy concentrations for understanding the exact nature of 


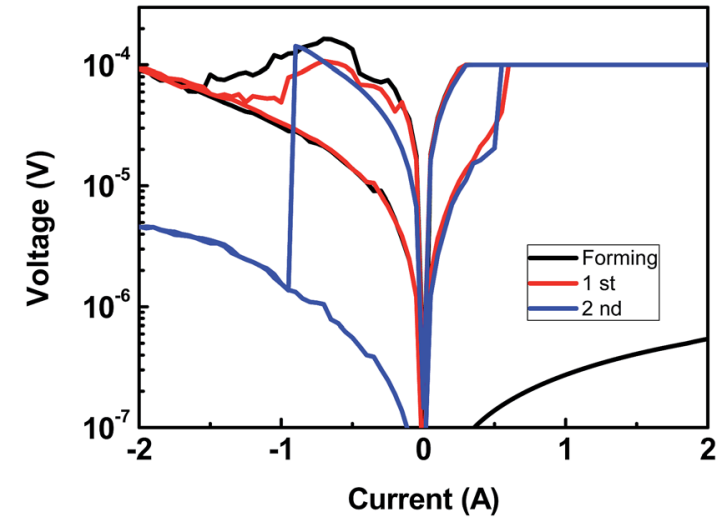

Fig. $6 \mathrm{I}-\mathrm{V}$ characteristic of $\mathrm{Pt} / \mathrm{AlO}_{x}\left(\right.$ water) $/ \mathrm{AlO}_{x}(\mathrm{OzO}$ en)/Pt structure. (a)

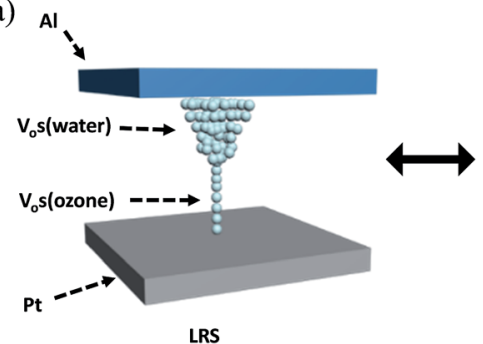

(b)

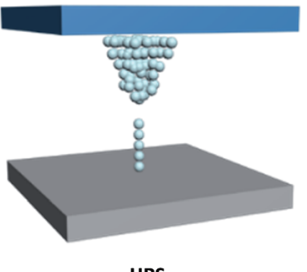

HRS
Fig. 7 Schematics illustration for switching mechanism.

defects in the resistive switching layer. We synthesized both oxide layers with the same thickness and conditions other than oxidizers (water vs. ozone), but the current-voltage response was very different. Although the exact vacancy concentration is not available it is possible to conclude that the defect concentration is very different according to oxidizers (Fig. S1 $\dagger$ ).

The cycling endurances of $\mathrm{Al} / \mathrm{AlO}_{x}($ water $) / \mathrm{AlO}_{x}$ (ozone) $/ \mathrm{Pt}$ devices were measured using consecutive ac voltage pulses to verify the electrical stability under $V_{\text {set }}=+2 \mathrm{~V}$ and $V_{\text {reset }}=-2 \mathrm{~V}$ (Fig. 8a). The width of the voltage pulse was $10 \mathrm{~ms}$ and the read voltage was $-0.3 \mathrm{~V}$. The endurance characteristics varied slightly over time, but both LRS and HRS states retained the memory window without failure for up to 500 cycles. To estimate the non-volatile memory characteristic, data retention tests were performed at RT, $85^{\circ} \mathrm{C}$ and $125^{\circ} \mathrm{C}$ (Fig. 8b). Both LRS and HRS were read at $-0.3 \mathrm{~V}$ for $10^{4} \mathrm{~s}$. The current fluctuated, but the memory window was not significantly degraded at any temperature. The stable retention property at elevated temperature $\left(85^{\circ} \mathrm{C}\right.$ and $\left.125{ }^{\circ} \mathrm{C}\right)$ indicates good reliability, and shows thermal stability with constant resistance ratio. From retention and endurance characteristics, we conclude that $\mathrm{Al} / \mathrm{AlO}_{x}($ water $) /$ $\mathrm{AlO}_{x}$ (ozone)/Pt RRAM devices have high uniformity and reliability.

In the $\mathrm{Al} / \mathrm{AlO}_{x}($ water $) / \mathrm{AlO}_{x}$ (ozone) $/ \mathrm{Pt}$ RRAM devices, conductive filaments remain stable in the $\mathrm{AlO}_{x}$ (water) layer but the filaments partially dissociated in the $\mathrm{AlO}_{x}$ (ozone) layer because the oxide layers have different amounts of $\mathrm{V}_{\mathrm{o}} \mathrm{s}$. Because filaments partially dissociated in the $\mathrm{AlO}_{x}$ (ozone) layer during

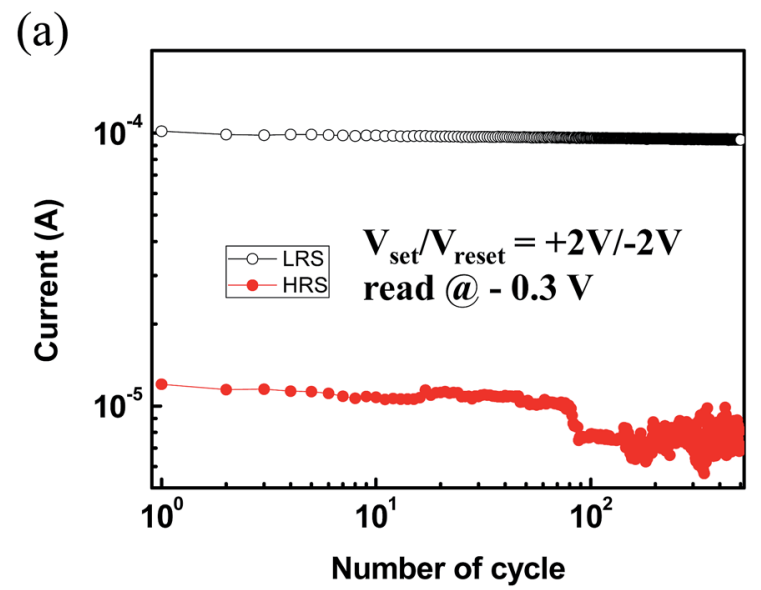

(b)

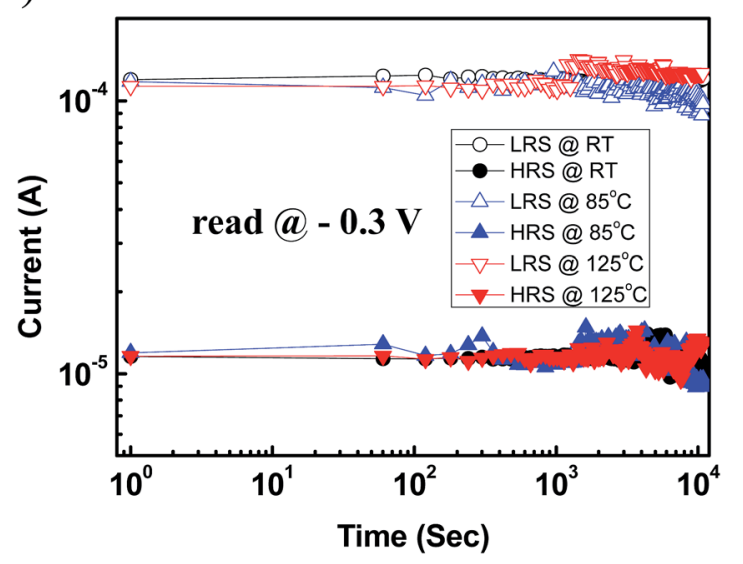

Fig. 8 Reliability of $\mathrm{Al} / \mathrm{AlO}_{x}$ (water)/AlO (ozone)/Pt devices. (a) Endurance measurement. (b) Data retention properties measured at RT, $85^{\circ} \mathrm{C}$, and $125^{\circ} \mathrm{C}$.

reset process, $\mathrm{Al} / \mathrm{AlO}_{x}($ water $) / \mathrm{AlO}_{x}$ (ozone)/Pt RRAM devices exhibit the gradual reset behavior and immune to hard breakdown. The set and reset processes are normally affected by the competition among different filamentary paths at randomly uncertain filament sizes, orientations, and locations, so the process has a random component. However the $\mathrm{Al} / \mathrm{AlO}_{x}($ water $) /$ $\mathrm{AlO}_{x}$ (ozone)/Pt RRAM devices have restricted set and reset area, resulting in good uniformity and reliability. To ensure the different amounts of $\mathrm{V}_{\mathrm{o}} \mathrm{s}$ between $\mathrm{AlO}_{x}$ (water) and $\mathrm{AlO}_{x}$ (ozone) layer, top electrode is active $\mathrm{Al}$ which contacts the $\mathrm{AlO}_{x}$ (water) layer and increases the number of $\mathrm{V}_{\mathrm{o}} \mathrm{s}$ in $\mathrm{AlO}_{x}$ (water).

In this experiment, we optimized the bilayer RRAM devices composed of $\mathrm{Al} / \mathrm{AlO}_{x}($ water $) / \mathrm{AlO}_{x}$ (ozone) $/ \mathrm{Pt}$ structures; to control the number of $\mathrm{V}_{\mathrm{o}} \mathrm{s}$, we used two oxidizers. When water was used as the oxidizer the $\mathrm{AlO}_{x}$ layer had more $\mathrm{V}_{\mathrm{o}} \mathrm{s}$ than when ozone was used as the oxidizer. Because the oxide layers have different amounts of $\mathrm{V}_{\mathrm{O}} \mathrm{S}$ conductive filaments remain stable in the $\mathrm{AlO}_{x}$ (water) layer which has a large number of $\mathrm{V}_{\mathrm{o}} \mathrm{s}$ but the filaments partially dissociated in the $\mathrm{AlO}_{x}$ (ozone) layer, which has relatively fewer $\mathrm{V}_{\mathrm{o}} \mathrm{s}$. Use of an active Al top electrode, can increase the number of $\mathrm{V}_{\mathrm{o}} \mathrm{s}$ in the $\mathrm{AlO}_{x}$ (water) layer. The devices exhibit reproducible and reliable RRAM characteristic due to 
partial dissociation of conductive filaments in the $\mathrm{AlO}_{x}($ ozone $)$ layer.

The main purpose of this work is to show the fabrication of reliable memory devices based on bilayer structure with the same oxide material by changing the oxidizer during deposition. This is very versatile and facile way to fabricate the bilayer structure with different defect concentrations. In addition, this method can simplify the fabrication processes and can effectively reduce the process cost/time.

\section{Conclusions}

We used ALD to fabricate RRAM devices composed of $\mathrm{Al} /$ $\mathrm{AlO}_{x}$ (water) $/ \mathrm{AlO}_{x}$ (ozone)/Pt structure. After the initial forming process, the devices exhibit reliable and reproducible bipolar resistive switching behavior. Set voltage $\left(V_{\text {set }}\right)$ was $0.6 \mathrm{~V}$ and reset occurred gradually after $-0.8 \mathrm{~V}$. Our devices exhibit stable bipolar switching behavior, switching endurance $>500$ cycles, and data retention for $10^{4} \mathrm{~s}$ at $125{ }^{\circ} \mathrm{C}$. The conduction mechanism was ohmic in LRS and trap-controlled SCLC in HRS. The resistive switching mechanism is related to migration of $\mathrm{V}_{\mathrm{o}} \mathrm{s}$, which form conductive filaments when an electric field is applied. Joule heating breaks the filaments in $\mathrm{AlO}_{x}$ (ozone) layer. Conductive filaments remain stable in the $\mathrm{AlO}_{x}$ (water) layer which has a large number of $\mathrm{V}_{\mathrm{o}} \mathrm{s}$, whereas the filaments partially dissociate in the $\mathrm{AlO}_{x}$ (ozone) layer. This work can be a good solution to fabricate reliable RRAM devices since the fabrication process is simple and only single resistive switching material is needed.

\section{Acknowledgements}

This work was supported by the Future Semiconductor Device Technology Development Program (10045226) funded by the Ministry of Trade, Industry and Energy (MOTIE), and Korea Semiconductor Research Consortium (KSRC). This work was also supported by National Research Foundation of Korea (NRF2015R1A2A1A15055918). In addition, this work was partially supported by Brain Korea 21 PLUS project (Center for Creative Industrial Materials).

\section{Notes and references}

1 R. Waser and M. Aono, Nat. Mater., 2007, 6, 833-840.

2 A. Sawa, Mater. Today, 2008, 11, 28-36.

3 R. Waser, R. Dittmann, G. Staikov and K. Szot, Adv. Mater., 2009, 21, 2632-2663.

4 H. Akinaga and H. Shima, Proc. IEEE, 2010, 98, 2237-2251.

5 E. Linn, R. Rosezin, C. Kugeler and R. Waser, Nat. Mater., 2010, 9, 403-406.

6 M. Di Ventra and Y. V. Pershin, Mater. Today, 2011, 14, 584591.

7 M. H. Lee and C. S. Hwang, Nanoscale, 2011, 3, 490-502.

8 M. J. Lee, C. B. Lee, D. Lee, S. R. Lee, M. Chang, J. H. Hur, Y. B. Kim, C. J. Kim, D. H. Seo, S. Seo, U. I. Chung, I. K. Yoo and K. Kim, Nat. Mater., 2011, 10, 625-630.
9 J. Park, K. P. Biju, S. Jung, W. Lee, J. Lee, S. Kim, S. Park, J. Shin and H. Hwang, IEEE Electron Device Lett., 2011, 32, 476-478.

10 T. Hasegawa, K. Terabe, T. Tsuruoka and M. Aono, Adv. Mater., 2012, 24, 252-267.

11 L. J. Zhang, R. Huang, M. H. Zhu, S. Q. Qin, Y. B. Kuang, D. J. Gao, C. Y. Shi and Y. Y. Wang, IEEE Electron Device Lett., 2010, 31, 966-968.

12 Z. Fang, H. Y. Yu, X. Li, N. Singh, G. Q. Lo and D. L. Kwong, IEEE Electron Device Lett., 2011, 32, 566-568.

13 J. W. Seo, S. J. Baik, S. J. Kang, Y. H. Hong, J. H. Yang and K. S. Lim, Appl. Phys. Lett., 2011, 98, 233505.

14 Y. Wu, S. M. Yu, B. Lee and P. Wong, J. Appl. Phys., 2011, 110, 094104.

15 S. Yu, H. Y. Chen, B. Gao, J. Kang and H. S. Wong, ACS Nano, 2013, 7, 2320-2325.

16 J.-M. Song and J.-S. Lee, Sci. Rep., 2016, 6, 18967.

17 Y. Wu, S. M. Yu, B. Lee and P. Wong, J. Appl. Phys., 2011, 110. 18 D. S. Jeong, R. Thomas, R. S. Katiyar, J. F. Scott, H. Kohlstedt, A. Petraru and C. S. Hwang, Rep. Prog. Phys., 2012, 75, 076502.

19 S. Lee, W. G. Kim, S. W. Rhee and K. Yong, J. Electrochem. Soc., 2008, 155, H92-H96.

20 S. Takata, R. Tanaka, A. Hachiya and Y. Matsumoto, J. Appl. Phys., 2011, 110, 103513.

21 S. S. Lee, E. S. Lee, S. H. Kim, B. K. Lee, S. J. Jeong, J. H. Hwang, C. G. Kim, T. M. Chung and K. S. An, Bull. Korean Chem. Soc., 2012, 33, 2207-2212.

22 W. Kim, S. I. Park, Z. P. Zhang and S. Wong, IEEE Trans. Electron Devices, 2014, 61, 2158-2163.

23 L. Assaud, M. Hanbuecken and L. Santinacci, in Atomic Layer Deposition Applications 8, ed. J. W. Elam, A. Londergan, O. VanDerStraten, F. Roozeboom, S. DeGendt, S. F. Bent and A. Delabie, 2012, pp. 151-157.

24 J. Hu and H. S. P. Wong, J. Appl. Phys., 2012, 111, 044105.

25 L. G. Wang, X. Qian, Y. Q. Cao, Z. Y. Cao, G. Y. Fang, A. D. Li and D. Wu, Nanoscale Res. Lett., 2015, 10, 135.

26 S. M. Sadaf, X. Liu, M. Son, S. Park, S. H. Choudhury, E. Cha, M. Siddik, J. Shin and H. Hwang, Phys. Status Solidi A, 2012, 209, 1179-1183.

27 A. Prakash, S. Maikap, C. S. Lai, T. C. Tien, W. S. Chen, H. Y. Lee, F. T. Chen, M. J. Kao and M. J. Tsai, Solid-State Electron., 2012, 77, 35-40.

28 R. C. Fang, Q. Q. Sun, P. Zhou, W. Yang, P. F. Wang and D. W. Zhang, Nanoscale Res. Lett., 2013, 8, 92.

29 Y. Bai, H. Q. Wu, Y. Zhang, M. H. Wu, J. Y. Zhang, N. Deng, H. Qian and Z. P. Yu, Appl. Phys. Lett., 2013, 102, 173503.

30 Y. Zhang, H. Wu, Y. Bai, A. Chen, Z. Yu, J. Zhang and H. Qian, Appl. Phys. Lett., 2013, 102, 233502.

31 H. Zhang, N. Aslam, M. Reiners, R. Waser and S. HoffmannEifert, Chem. Vap. Deposition, 2014, 20, 282-290.

32 C. W. Hsu, Y. F. Wang, C. C. Wan, I. T. Wang, C. T. Chou, W. L. Lai, Y. J. Lee and T. H. Hou, Nanotechnology, 2014, 25, 165202.

33 C. Y. Huang, C. Y. Huang, T. L. Tsai, C. A. Lin and T. Y. Tseng, Appl. Phys. Lett., 2014, 104, 062901. 
34 C.-T. Chou, B. Hudec, C.-W. Hsu, W.-L. Lai, C.-C. Chang and T.-H. Hou, Microelectron. Reliab., 2015, 55, 2220-2223.

35 H. J. Lee, M. H. Park, Y. S. Min, G. Clavel, N. Pinna and C. S. Hwang, J. Phys. Chem. C, 2010, 114, 12736-12741.
36 O. B. F. Campabadal, M. Zabala, M. C. Acero and J. M. Rafí, Proceedings of the 8th Spanish Conference on Electron Devices, 2011.

37 L. E. Yu, S. Kim, M. K. Ryu, S. Y. Choi and Y. K. Choi, IEEE Electron Device Lett., 2008, 29, 331-333.

38 E. Lim and R. Ismail, Electronics, 2015, 4, 586-613. 